June 1991

\title{
Re-visioning Group Psychotherapy Training in Psychiatry
}

Len Sperry, M.D., Ph.D.

Medical College of Wisconsin, Milwaukee, Wisconsin

Follow this and additional works at: https://jdc.jefferson.edu/jeffjpsychiatry

Part of the Psychiatry Commons

Let us know how access to this document benefits you

\section{Recommended Citation}

Sperry, M.D., Ph.D., Len (1991) "Re-visioning Group Psychotherapy Training in Psychiatry," Jefferson Journal of Psychiatry. Vol. 9 : Iss. 2 , Article 11.

DOI: https://doi.org/10.29046/JJP.009.2.007

Available at: https://jdc.jefferson.edu/jeffjpsychiatry/vol9/iss2/11

This Article is brought to you for free and open access by the Jefferson Digital Commons. The Jefferson Digital Commons is a service of Thomas Jefferson University's Center for Teaching and Learning (CTL). The Commons is a showcase for Jefferson books and journals, peer-reviewed scholarly publications, unique historical collections from the University archives, and teaching tools. The Jefferson Digital Commons allows researchers and interested readers anywhere in the world to learn about and keep up to date with Jefferson scholarship. This article has been accepted for inclusion in Jefferson Journal of Psychiatry by an authorized administrator of the Jefferson Digital Commons. For more information, please contact: JeffersonDigitalCommons@jefferson.edu. 


\title{
Re-visioning Group Psychotherapy Training in Psychiatry
}

\author{
Len Sperry, M.D., Ph.D.
}

\begin{abstract}
The literature on group training in psychiatry reveals that most residency programs include didactic seminars but few offer supervised group therapy experience or require competence in referral for group therapy. Not surprisingly, research shows that few residents utilize group therapy-either leading a group or making referrals to groups - after graduation. This paper reviews the current "vision" of group training and offers an alternate vision. The assumptions, group formats and competencies of this new vision are described. Emphasized are the development of skills and competency of making appropriate referrals to groups, which may positively impact resident attitudes and practice patterns regarding group therapy.

Training in group psychotherapy is required by the ACGME for accrediting programs in psychiatry (1). However, the amount, type, and quality of training is extraordinarily variable, and the outcomes leave much to be desired (2-4). Underlying this variability is the current dominant "vision" of group training. This paper describes the common elements of this vision and its impact on residents during and after training, and then proposes an alternative vision for group psychotherapy training that could more positively influence and impact resident attitudes and practice patterns.
\end{abstract}

\section{THE GURRENT STATUS AND VISION OF GROUP THERAPY TRAINING}

In the past 20 years the increase in the number of programs offering group therapy training has more than doubled from 40 percent in 1970 (5) to 78.5 percent in 1977 (6) and 91 percent in 1986 (1). Across these programs four different modes of group training are utilized: didactic seminars, observation of group process, the experience of being a group member, and supervised leadership in an actual group. By far, the didactic seminar is the primary mode of training being used in 95.6 percent of residencies surveyed by Pinney (1).

A review of the literature regarding the perception of trainees, clinicians, and group therapy supervisors about the effectiveness and impact of the various modes of group training is revealing. Salvendy, Robson and Babiak (7) surveyed 114 psychiatry residents at the University of Toronto about their training and attitudes toward group therapy. Not surprisingly, the residents with the most hours of supervised experience leading groups had the most positive attitudes toward group therapy, and 
believed that they would utilize group interventions in their future practice. An unexpected finding was that the only positive correlation with didactic seminar learning was that residents achieved some basic knowledge for written speciality exams. Kahn, White and Hawkins (8) surveyed practicing psychiatrists in North Carolina about their utilization of group therapy after residency training. They found that while 25 percent of practicing psychiatrists had a supervised experience leading a group during their residency, only 28 percent of them incorporated group therapy in their practice. Of particular note was that didactic seminars did not influence clinicians' perceptions of either their adequacy to lead groups or refer patients to them, as compared with supervised experience leading a group. Similarly, Yalom (9) laments that the didactic seminar is the least effective mode of group training.

If didactic seminars are so ineffective why do most residencies emphasize them? The answer appears to have both theoretical and practical aspects. Yalom (10) argues that it is common knowledge that psychiatrists have long been alienated from the field of group therapy, rarely lead groups in inpatient settings, outpatient clinics or private practice settings and that psychiatry has become increasingly re-medicalized and less committed to psychotherapy in general, and group therapy in particular. Furthermore, group therapy is viewed by many psychiatrists as a second rate treatment that is superficial, may be dangerous, and useful only if individual therapy is unavailable (10).

There are some practical explanations for the limited amount of group therapy training in residency programs. First, establishing useful and workable group therapy rotations in an academic calendar is difficult and unwieldy, particularly if a group therapy experience is envisioned as the traditional long-term, ongoing group with a dynamic or interpersonal focus. Usually these are "heterogeneous," meaning members do not share a specific, common symptom or concern and differ in age, sex, background and personality traits, compared with "homogeneous" groups, which are targeted at a specific symptom or concern shared by all members $(13,14)$. In my experience such groups demand considerable time and effort to screen potential members, complex scheduling and staffing, as well as considerable overhead expenses. Second, insisting that residents develop competency in the practice of group therapy as per the suggested guidelines of the American Group Psychotherapy Association would necessitate a major restructuring of residency training programs.

Yalom (9) offers a design for training that is similar to the American Group Psychotherapy Association guidelines. He believes that an adequate training experience involves the observation of experienced clinicians, group therapy supervision, experiential group participation and personal therapy for the trainee. These four elements, he contends, constitute the minimum to train group therapists. Parenthetically, he does not believe that there is any correlation between a didactic seminar and competence to lead groups. While Yalom has not articulated specific clinical skills or outcome objectives for trainees, other psychiatric educators have. McCarley, Yamamoto, Steinberg, and Anker (11) describe six basic and necessary clinical skills in training outcomes, while the edited training handbook by Thompson (12), $A$ Resident's Guide to Psychiatric Education lists nine enabling objectives and four competen- 
cies for training psychiatric residents in group therapy. Since access to ongoing long term groups is problematic, these minimum training requirements $(9,11,12)$ are unlikely to be implemented by many residency programs.

Not surprisingly, the ease of scheduling and staffing a didactic seminar provides the residency director with a reasonable alternative to the "ideal" group training experience. The didactic seminar allows for residencies to technically meet ACGME guidelines, but at the price of limiting residents' access to a whole range of treatment options. Essentially then, the "vision" of group therapy training common to most residency programs appears to be based on four assumptions: (1) an adequate group therapy experience consists of supervised experience with long-term, ongoing dynamic or interpersonally focused groups with a heterogeneous membership composition; (2) many psychiatrists are not convinced that group therapy is effective and appropriate treatment, and even if they do, relatively few utilize groups in their clinical practice; (3) there are significant difficulties in scheduling, setting up, staffing and funding such long-term groups; (4) therefore, the only reasonable training mode for meeting ACGME requirements is the didactic seminar whose basic objective is to provide knowledge about groups.

\section{AN ALTERNATIVE VISION OF GROUP PSYCHOTHERAPY TRAINING}

Unfortunately, this approach is all too common in American psychiatric education. Basically, I believe that an alternate vision of group therapy training involving a somewhat different set of assumptions, group formats and competencies is needed. This section describes these assumptions, formats and competencies.

Let's consider the matter of assumptions underlying the alternate vision. First, an adequate training experience in group therapy and interventions involves exposure to a wide variety of homogeneous and heterogeneous groups, both long-term and time-limited. Second, group therapeutic interventions may be as or more effective than individual therapy, given a patient's differential needs and style relative to the indications, contradictions and enabling factors for various group formats. Third, although there may be difficulties in setting up and maintaining long-term heterogeneous groups, this is seldom the case with time-limited homogeneous groups. And fourth, it is conceivable that residents can be expected to develop minimal level of both knowledge and competence with group process.

This re-visioning of group training involves reconceptualizing the terminal objectives and competencies of training in group therapy. Group therapy training would provide a panoramic view of a variety of group interventions, as well as limited experience with at least four group formats (cf. Table 1). There would be at least two outcomes for group training: competency in referring patients to appropriate groups, and competency in leading groups. In the first instance, a specially designed didactic seminar might be sufficient, whereas it would not be for the second competency. A basic graduation requirement would require demonstrated knowledge and competency in appropriately referring patients, while the group practice competency would be an elective requirement. Both competencies could be assessed with case simula- 
tions and standardized rating scales (11). The didactic seminar format could remain the primary mode of instruction, but would have specified objectives, skill-based instruction and learning experiences, and a competency-based assessment schema. The basic expectation would be that residents know and appreciate the value of group interventions, cognizant of specific indications, contraindications and patient enabling factors, and make appropriate referrals.

Competency in making referrals for group treatment is not an isolated skill. Actually, the ability to make appropriate group referrals is one aspect of the skill of treatment selection. Frances, Perry and Clarkin (13) describe five sets of treatment decisions that clinicians routinely make in selecting treatment: 1) setting: where the treatment takes place, i.e., hospital, medical ward, private office; 2) time: the length and frequency of session and the duration of treatment; 3) approach: the specific treatment techniques and shared treatment objectives; 4) somatic treatment: the need for medication, ECT or other medical interventions; and 5) format: whether treatment will take place primarily in an individual, marital, family, or group mode, or some combination. Irrespective of their level of awareness, clinicians routinely make these five decisions about treatment selections, and it is generally maintained that this process of treatment selection should be more reflective than reflexive.

Regarding treatment format decisions, the best decisions are those incorporating knowledge of the indications, contraindications, and enabling factors for all treatment formats, including groups. Frances, Perry and Clarkin (13) have articulated such criteria for the individual, family, marital, and group modes of treatment. Toseland and Siporin (15) have also described the indications and contraindications for group treatment based on their extensive review of the group research literature. The number of group formats has expanded greatly in the past five years. For instance, Vinogradov and Yalom describe over 20 such formats (16) and these are a mere sampling of the many formats. Group treatment can be subdivided into heterogeneous and homogeneous groups $(13,14)$, and groups can be long-term and ongoing or time-limited.

In hetergeneous groups a feeling of commonality develops wherein patients realize they are not alone. Gradually, as the patient feels more accepted, accepting and acceptable, he or she is more capable of taking interpersonal risks inside and outside the group. Interactions offer group members a chance to correct distortions about others and themselves and to alter maladaptive responses with little likelihood of engaging in regressive transferential-countertransferential involvement with therapists. A major advantage of the heterogeneous group is cost-effectiveness. In addition, this group format is particularly useful for patients who present with interpersonal problems. The major disadvantages include relatively low patient acceptance and high dropout rates (13). Furthermore, some patients have urgent problems that demand more immediate, intense, and individualized treatment than a group format can realistically provide. Generally speaking, heterogeneous groups tend to be suited for longer-term formats.

Compared to heterogeneous groups, the range of interaction in homogeneous groups tends to be more restrictive. These groups provide a structured social network 
for individuals who previously felt they must suffer their problem in isolation. Unlike heterogeneous groups, homogeneous groups have the advantage of greater acceptance by the patient and more acceptance by the group towards most members. This format also helps to reduce the patient's sense of isolation and demoralization and allows him or her to be helpful to others. Often these groups deal with problems for which there is no other available effective treatment. The major limitation of these groups is their narrow focus, which may allow other important issues to be missed (14).

Generally speaking, homogeneous groups tend to be more time-limited than heterogeneous groups. Table 1 lists some representative types of heterogeneous and homogeneous groups.

Competency in referral would be the goal of the didactic seminar. Ideally, the seminar would include topics such as: therapeutic factors in group therapy; group cohesiveness and negative contagion; homogeneous and heterogeneous groups; long-term and time-limited groups; differential treatment selection including indications, contraindications, and patient enabling factors for various group modalities as compared to individual, marital and family formats; dealing with difficult patients; and the stages of group treatment.

TABLE 1.

Some Representative Homogeneous and Heterogeneous Group Formats

\begin{tabular}{ll}
\hline Homogeneous Groups & Heterogeneous Groups \\
\hline TIME-LIMITED & OUTPATIENT \\
Professionally Led: & Dynamic \\
Depression & Interpersonal \\
Bipolar & Behavioral \\
Anxiety Disorders & Psychodrama \\
Agoraphobia & Aftercare Groups \\
Obsessive Ciompulsive Disorder & Medication Groups \\
Borderline Personality Disorder & Day Hospital Groups \\
Bulimia and Anorexia & \\
Multiple Personality & INPATIENT \\
Spouse Batterer's & Dynamic \\
Incest Survivors & Interpersonal \\
Weight Control & Behavioral \\
Smoking Cessation & Psychodrama \\
Substance Dependence & \\
Pain Management & \\
Support Groups/Lay Led: & \\
AA, Alateen, Alanon & \\
NA, OA, ACOA & \\
Manic Depressive Association Groups & \\
AWAKE & \\
Recovery, Inc. & \\
&
\end{tabular}


In this proposal, assessing trainees' competency to make appropriate referrals for group treatment is essential. Written case material or simulations could be used to evaluate trainees' understanding of the patient's needs, style and motivation for treatment. This assessment could also evaluate trainees' knowledge of indications, contraindications and enabling factors for the various modes of treatment, be they individual, marital or family, and group therapy. Essentially, trainees would demonstrate specific knowledge about the indications and contraindications for the various homogeneous, heterogeneous, long-term and time-limited types of groups. Ideally, trainees would have the opportunity to observe several different heterogeneous and homogeneous group formats including time-limited and long-term groups.

Case conferences on various required rotations could also emphasize the treatment selection process. Thus, trainees would have multiple opportunities outside the formal didactic group seminar to consider the question of treatment setting and mode whether it be individual, marital or family, group, or some combination.

The competency for leading groups assumes the minimal level of competency for group referrals. In addition, it requires observation of group process, the experience of being a group member, and the experience of running a group along with close supervision. This competency and its various learning objectives have been specified in considerable detail by other psychiatric educators $(11,13,14)$.

\section{CONCLUSION}

A review of the literature in group psychotherapy training in psychiatry grimly portrays the current state of affairs. On the one hand, psychiatric educators and group therapy writers have articulated a number of terminal objectives and minimal competencies for the ideal training of residents in group psychotherapy. On the other hand, the reality of the situation is that few residency programs operationalize and embody these objectives and competencies. Because of both ideological and practical consideration, which I have designated as the "current vision" of group psychotherapy training, the didactic seminar in group therapy is the primary mode of training in the majority of residency programs. Except for providing the resident with a knowledge base for speciality board exams, the didactic seminar does little to engender positive attitudes about the usefulness or effectiveness of groups, nor do studies suggest it influences the trainee's practice pattern of leading groups or referring patients to groups either during or after residency.

Subsequently, this paper proposes re-visioning group psychotherapy training to focus on the competency of referrals for groups rather than mere knowledge about groups. This competency could be achieved within the context of a didactic group seminar emphasizing the skills of treatment selection and referral. Furthermore, the skill of treatment referral would be objectively assessed and minimum competence would be required for graduation from the residency program. Finally, this proposal supports the achievement of competency to practice group therapy endorsed by other psychiatric educators, but this competency would be an elective requirement. 


\section{REFERENCES}

1. Pinney E: Group psychotherapy training in psychiatric residencies. Journal of Psychiatric Education 10:106-112, 1986

2. Horowitz L: Training groups for psychiatric residents. Int J Group Psychother 17:421-435, 1967

3. Sadock BJ, Kaplan HI, Freedman AM: Integrated group psychotherapy training and psychiatric residency. Arch Gen Psychiatry 18:276-279, 1978

4. Yager J, Pasnau RO: The educational objectives of a psychiatric residency program. Am J Psychiatry 133:217-220, 1976

5. Sadock B and Kaplan H: Training and standards in group psychotherapy. In H. Kaplan and B. Sadock (eds.). Comprehensive Group Psychotherapy. Baltimore: Williams and Wilkins, 1971

6. Pinney E, Wells S, Fisher B: Group therapy training in psychiatric residency programs: A national survey. Am J Psychiatry 135:1505-1508, 1978

7. Salvendy JT, Robson B, Babiak T: Group psychotherapy in psychiatry residency training. Academic Psychiatry 14:27-33, 1990

8. Kahn EM, White EM, Hawkins DM: Training in group psychotherapy: Residency experience, use in practice and self-perception of competence. Journal of Psychiatric Education 10:204-211, 1986

9. Yalom ID: The Theory and Practice of Group Psychotherapy. New York: Basic Books, 1985

10. Yalom ID: Group psychotherapy: Forward to section VI. In AJ Frances and RE Hales (eds.). Psychiatric Update: The American Psychiatric Association Annual Review, Volume 5. Washington, DC: American Psychiatric Press, 1986

11. McCarley T, Yamamoto J, Steinberg A, Anker M: Teaching group psychotherapy. In M Grotjuhn, FM Kline, CT Friedman (eds.). Handbook of Group Therapy. New York: Van Nostrand Reinhold, 1985

12. Thompson MG: A Resident's Guide to Psychiatric Education. New York: Plenum Medical Book Co., 1979

13. Frances A, Clarkin J, Perry S: Differential Therapeutics in Psychiatry: The art and science of treatment selection. New York: Brunner/Mazel, 1984

14. Perry S, Frances A, Clarkin J: A DSM-III-R Casebook of treatment selection (2 ed). New York: Brunner/Mazel, 1990

15. Vinogradov S, Yalom I: Concise guide to group psychotherapy. Washington, DC: American Psychiatric Press, 1989

16. Toseland RW, Siporin M: When to recommend group treatment: a review of the clinical and research literature. Intl J Group Psychother 36:171-201, 1986 